Images in...

\title{
Urethral obstruction secondary to an intraprostatic stent
}

\author{
Deirdre Mary Fanning, Hugh Flood \\ Department of Urology, Midwestern Regional Hospital, Limerick, Ireland \\ Correspondence to Deirdre Mary Fanning, fanningdee@yahoo.co.uk
}

\section{DESCRIPTION}

An 82-year-old male presented to the Emergency Department secondary to urinary incontinence. He was systemically well. He had a background of prostate cancer diagnosed and treated with brachytherapy 17 years ago. He reported having undergone a cystoscopic procedure 3 years ago for treatment of acute urinary retention. Since this procedure, he had suffered from progressively worsening urinary incontinence. All prior medical treatment was in a foreign country.

Renal function was within normal limits. His PSA was measured at $<0.02 \mathrm{ng} / \mathrm{ml}$. Bladder scan showed

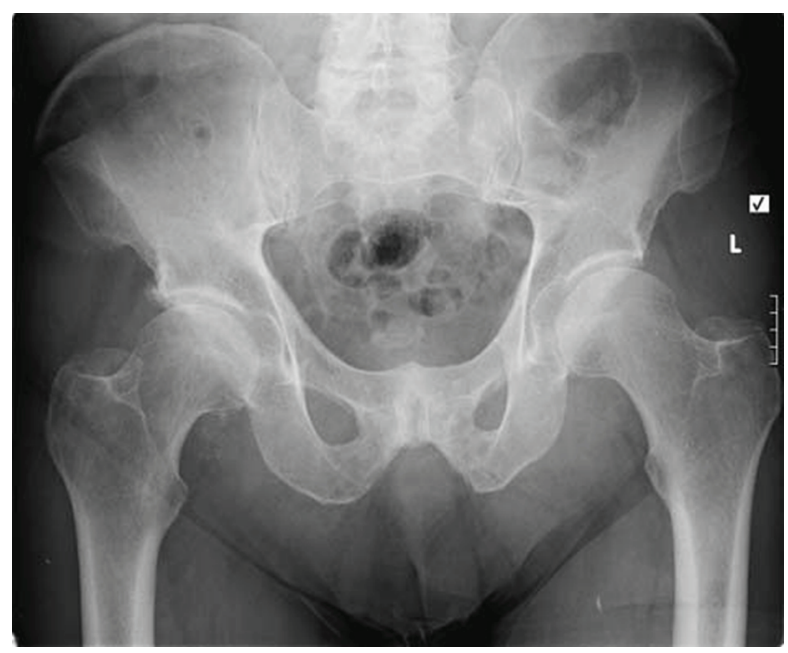

Figure 1 Plain film of the pelvis showing a calcified intraprostatic stent overlying the pubic symphysis. approximately $100 \mathrm{ml}$ of urine within the bladder. Attempts at urethral catheterisation failed. Plain film of the abdomen showed a grossly calcified intraprostatic urethral stent (figure 1). ${ }^{1}$ He proceeded to undergo laser destruction of his heavily calcified intraprostatic stent. There was no evidence of prostatic tissue ingrowth or bladder mucosal abnormality. The stent dislodged intra-operatively and migrated to the bladder. It was removed via a suprapubic cystotomy (figures 2 and 3). He made a good postoperative recovery. His urinary incontinence persisted and was managed with containment devices. He refused any further intervention.

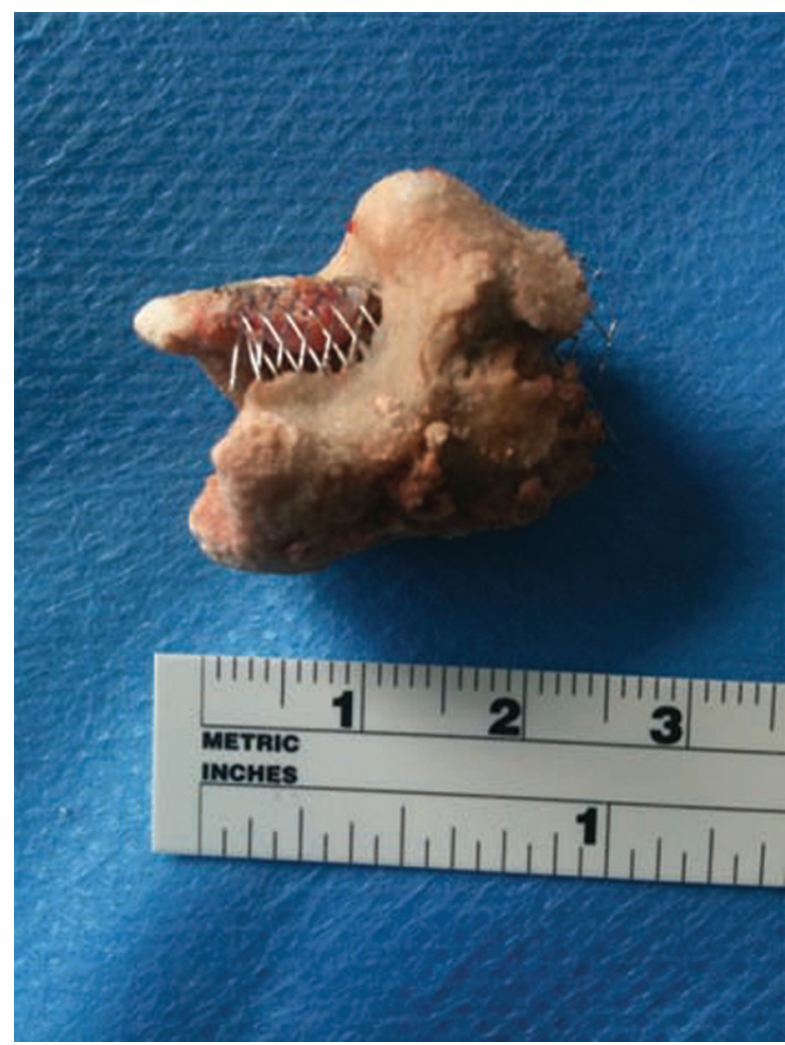

Figure 2 The calcified intraprostatic stent is shown, measuring approximately $2.5 \mathrm{~cm}$ in length. The area which was lasered is clearly evident. 


\section{BMJ Case Reports}

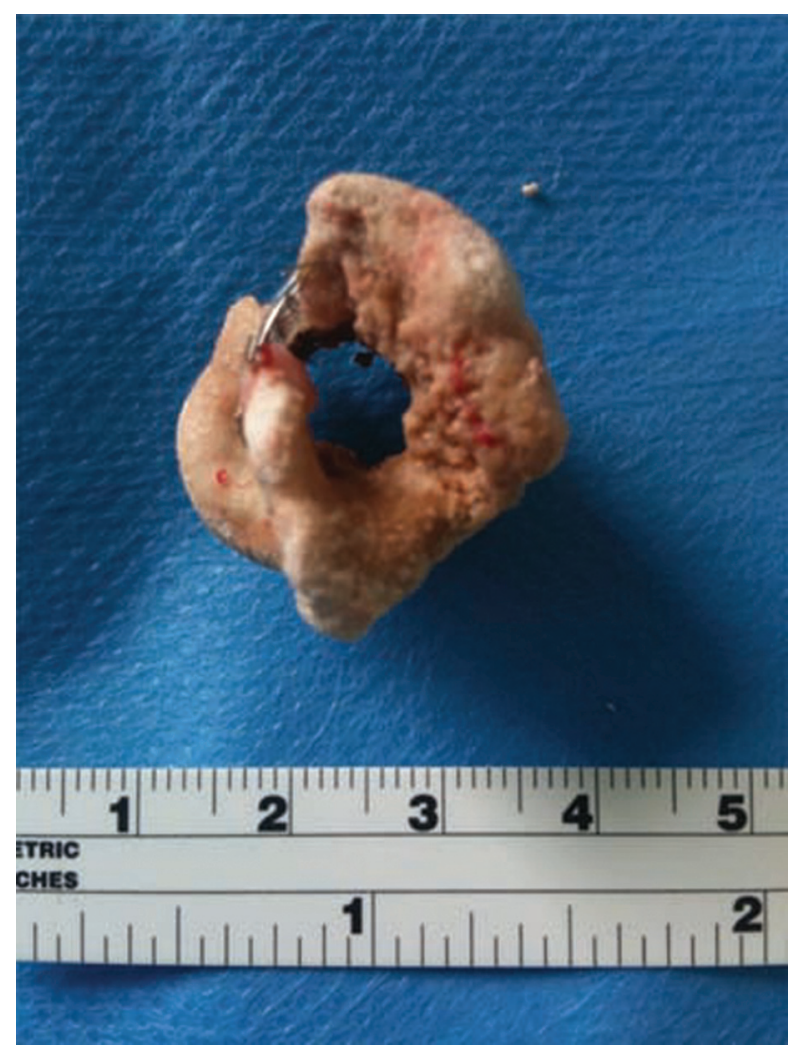

Competing interests None.

Patient consent Obtained.

\section{REFERENCE}

1. Perry MJ, Roodhouse AJ, Gidlow AB, et al. Thermo-expandable intraprostatic stents in bladder outlet obstruction: an 8-year study. BJU Int 2002;90:216-23.

Figure 3 The calcified intraprostatic stent is shown, measuring approximately $2.5 \mathrm{~cm}$ in diameter. The area which was lasered is clearly evident. 